\title{
Repetitive transcranial magnetic stimulation treatment for peripartum depression: systematic review \& meta-analysis
}

Hyune June Lee, Sung Min Kim and Ji Yean Kwon * (D)

\begin{abstract}
Background: Peripartum depression is a common disorder with very high potential hazards for both the patients and their babies. The typical treatment options include antidepressants and electroconvulsive therapy. However, these treatments do not ensure the safety of the fetus. Recently, repetitive transcranial magnetic stimulation has emerged as a promising treatment for neuropathies as well as depression. Nevertheless, many studies excluded pregnant women. This systematic review was conducted to confirm whether repetitive transcranial magnetic stimulation was a suitable treatment option for peripartum depression.

Methods: We performed a systematic review that followed the PRISMA guidelines. We searched for studies in the MEDLINE, PsycINFO, EMBASE, and Cochrane library databases published until the end of September 2020. Eleven studies were selected for the systematic review, and five studies were selected for quantitative synthesis. Data analysis was conducted using Comprehensive Meta-Analysis 3 software. The effect size was analyzed using the standardized mean difference, and the $95 \%$ confidence interval $(\mathrm{Cl})$ was determined by the generic inverse variance estimation method.
\end{abstract}

Results: The therapeutic effect size of repetitive transcranial magnetic stimulation for peripartum depression was 1.394 (95\% Cl: 0.944-1.843), and the sensitivity analysis effect size was 1.074 (95\% Cl: 0.689-1.459), indicating a significant effect. The side effect size of repetitive transcranial magnetic stimulation for peripartum depression was 0.346 (95\% Cl: 0.214-0.506), a meaningful result. There were no severe side effects to the mothers or fetuses.

Conclusions: From various perspectives, repetitive transcranial magnetic stimulation can be considered an alternative treatment to treat peripartum depression to avoid exposure of fetuses to drugs and the severe side effects of electroconvulsive therapy. Further research is required to increase confidence in the results.

Keywords: Repetitive transcranial magnetic stimulation, rTMS, Peripartum depression, Pregnancy

\footnotetext{
* Correspondence: jykwon@dgu.ac.kr

Department of Medical Devices Industry, Dongguk University, Seoul, South Korea
}

(c) The Author(s). 2021 Open Access This article is licensed under a Creative Commons Attribution 4.0 International License, which permits use, sharing, adaptation, distribution and reproduction in any medium or format, as long as you give appropriate credit to the original author(s) and the source, provide a link to the Creative Commons licence, and indicate if changes were made. The images or other third party material in this article are included in the article's Creative Commons licence, unless indicated otherwise in a credit line to the material. If material is not included in the article's Creative Commons licence and your intended use is not permitted by statutory regulation or exceeds the permitted use, you will need to obtain permission directly from the copyright holder. To view a copy of this licence, visit http://creativecommons.org/licenses/by/4.0/ The Creative Commons Public Domain Dedication waiver (http://creativecommons.org/publicdomain/zero/1.0/) applies to the data made available in this article, unless otherwise stated in a credit line to the data. 


\section{Background}

Peripartum depression (PPD) is defined as major depression occurring within the gestational period and 4 weeks after childbirth [1]. PPD is a common disease that $10 \sim$ $15 \%$ of pregnant women experience (https://www.who. int/mental_health/maternal-child/maternal_mental_ health/en/), and PPD patients incur a massive lifetime expense of 75,728 pounds (USD \$95,656) [2]. PPD threatens not only the mother's health by causes hormonal imbalance [3], alcohol and substance abuse [4], and more than 5-fold increased maternal suicide [5]. The health of the fetus is also affected by premature birth (the effect size of peripartum depression on premature birth is 1.38) [6], and low birth weight (the effect size of peripartum depression on low birth weight is 1.3) [7]. PPD also interferes with creating a stable attachment in infants 'growth process, which can result in self-control and cognitive function behavioral issues [8].

The methods for treating PPD are mainly electroconvulsive therapy (ECT) and antidepressants [9]. Although both have proven treatment effectiveness for PPD [1013], some concerns for the safety of pregnant women and fetuses have been raised. Antidepressants relieve depression by regulating the neurotransmitters that make people feel happy [14]. Neurotransmitters released from pre-synaptic neurons are reabsorbed or decomposed by monoamine oxidase enzymes to transfer them to the neurons from the synapses Antidepressants reduce neurotransmitter decomposition by interfering with their reabsorption and the activity of monoamine oxidase enzymes, thereby alleviating depression [15]. Antidepressants are one of the most used treatment methods for PPD, but there are some concerns. Because components of antidepressants can pass through the placenta [16], these could have a chemical effect on the fetus. Pregnant women taking SSRI have a 7-fold increased risk of spontaneously induced abortion [17, 18], more than 3-fold increased risk of fetal infections [19], and increased risks of premature birth and underweight babies [20], autism spectrum disorder in the baby [21], increased risk of motor, speech, and scholastic disorder [22], cardiac defects [23] and persistent pulmonary hypertension [24]. Also, infants can be exposed to antidepressants and their metabolites during breastfeeding [25], which could increase monoamine oxidase levels and affect the functional maturity of the infant's brain [26]. Side effects, such as decreased feeding [27], colic, and irritability [28] have been reported. Another treatment, ECT, is delivering a stimulating electrical shock to the brain to relieve depression. Electric shocks affecting neurons and chemicals in the brain produce short and controlled seizures, which have excellent effects on various neurological disorders [29]. However, treating pregnant women with ECTs can cause adverse effects such as vaginal bleeding and miscarriage [30], uterine contractions [31], abdominal pain [32], and preeclampsia [33]. Clinicians recommend these treatments because the risk of the treatment is smaller than the risk of PPD $[34,35]$ and their effectiveness has been proven. However, considering these treatment's safety concerns for the fetus and mother, research to identify safer treatment methods is needed.

With the recent development in brain stimulation research, many researchers are increasingly trying to use brain stimulation for various neurological treatments [36]. One type of brain stimulation, repetitive transcranial magnetic stimulation (rTMS), stimulates the brain's dorsolateral prefrontal cortex (DLPFC) with magnetic fields to induce the degeneration of neurons and activate the neural system of the brain to relieve depression [37]. Using rTMS to treat PPD is still reluctant [38-40], although studies have shown that rTMS is safe [41] and effective for treating several neurological diseases [42-44].

Thus, in this paper, we conducted a systematic review and meta-analysis to confirm whether rTMS treatment was suitable for PPD. There are few systematic review studies on rTMS treatment for PPD [45-48], but no studies statistically analyzed the therapeutic effects and safety and considered the adverse effects on fetuses. To investigate these problems, we conducted a metaanalysis to confirm the effect size of the therapeutic effects and safety and extended the range of patients from pregnant patients to 1 year after childbirth to identify the effect on the fetuses.

\section{Methods}

The systematic review followed the PRISMA guidelines (registration number CRD42020197855) [49].

\section{Key questions}

The criteria used in selecting the relevant studies included patients from the pregnancy period to 1 year after childbirth, intervention with TMS, no limits on the comparators, and outcomes measured by the degree of depression alleviation. The detailed key questions were:

(1) Is rTMS effective for PPD? What is the effect size of rTMS for PPD?

(2) Does rTMS have maternal and fetal side effects? What is the effect size of the side effects caused by rTMS?

\section{Inclusion and exclusion criteria}

In general, the studies used for the meta-analysis were randomized controlled trials (RCTs), but non-randomized studies (NRS) were also included in the meta-analysis, and case studies were included in the systematic review because only a small number of randomized trials provided evidence of the effects of the interventions [50] associated with pregnancy. Before inclusion, the non-randomized 
studies were evaluated to verify that the patients, interventions, comparisons, and outcomes were set appropriately by the Cochrane algorithm. If systematic reviews or metaanalyses were included, we checked the included studies and references. The criteria for exclusion were (1) experimental studies with animals, (2) studies not published in English, (3) studies that were not original (if there was only abstract, the original text was requested in an e-mail to the author), (4) symptoms of baby blues or postpartum psychosis, and (5) major depressive disorder that did not occur from pregnancy to 1 year after childbirth.

\section{Literature search strategy}

We performed a literature search of studies published before the end of September 2020 using EMBASE, MEDLINE, PsycINFO, and the Cochrane Library. In the literature search, the medical indications and treatment methods were searched using Boolean models. The indications search terms were using peripartum depression or antepartum depression or postpartum depression or pregnancy or perinatal, and the treatment searches were using rTMS or repeated transcranial magnetic stimulation or TMS or transcranial magnetic stimulation. If there were mapping or mesh term, it was used, otherwise it was extensive mode. The detailed search strategies are presented in Fig. 1. To minimize the omission of data and increase reliability, HJL, and JYK independently reviewed the literature and, if the opinions of the researchers differed, the studies were reviewed together, and an agreement was reached.

\section{Data extraction}

For the final selected literature, the following data were extracted: basic information (the title of paper, author, year of publication), study characteristics (study design, number of subjects), subject information (age, primary psychiatric diagnosis, gestational age, and simultaneous treatment), treatment parameters (motor threshold, site of stimulation, frequency and pulse, interval time, number of sessions) [51] and the result (outcome measure at baseline and at the end of treatment, side effects on mothers and fetuses).

\section{Risk of bias assessment}

After the literature screening, a bias evaluation of the studies was performed by two evaluators independently to clarify ambiguous differences between the reporting quality and research quality. Different evaluation methods were applied according to the study design. RCT studies were examined using the risk-of-bias 2 (ROB2) tool [52], and the NRS were examined using the Risk of Bias Assessment Tool for Non-randomized Studies (ROBINS-I) [53]. Case reports and series were evaluated used the methodological quality tool [54] because they could be adopted as evidence of new treatments [55]. The final judgment on the overall risk of bias was agreed upon between the two evaluators, and publication bias was visually reviewed through funnel plots, and additionally, statistically confirmed through Egger's regression.

\section{Data analysis}

Data analysis was conducted using Comprehensive Meta-Analysis 3 software (CMA3). The effect size was

\section{Searching strategy}

\author{
1. antepartrum depression.mp \\ 2. postpartum depression.mp \\ 3. peripartum depression.mp \\ 4. rTMS.mp \\ 5. Exp. repetitive Transcranial \\ Magnetic Stimulation \\ 6. Respetitive Transcranial \\ Magnetic Stimulation.mp \\ 7. TMS.mp \\ 8. Transcranial Magnetic \\ Stimulation.mp \\ 9. 4 or 6 or 7 or 8 \\ 10. 1 or 2 or 3 \\ 11. 10 and 9
}

12. antenatal period.mp

13. postnatal period.mp

14. pregnanacy.mp

15. exp. perinatal

16. Major depressive disorder.mp

17. Depression.mp

18. Exp. Mental illness

19. Exp. Serious mental illness

20. 12 or 13 or 14 or 15

21.17 or 18 or 19

22. 20 dnd 21 and 9

23. 11 or 22

Fig. 1 Searching strategy 
used standardized mean difference (SMD) was obtained using two-group, pre-post data in the RCTs, and one group pre-post data for the NRS [56]. For the 95\% CI and the correlation coefficient value of 0.5 , the generic inverse variance estimation method was used [57]. Safety was assessed using the effect size of the side effects, and the effect size was calculated by the same method as the treatment effect. The calculations are presented as a Forest plot. Heterogeneity was determined using the statistical test method Cochrane's Q test and the Isquared $\left(\mathrm{I}^{2}\right)$ statistic. If the $p$-value of the $\mathrm{Q}$ test value exceeded 0.1 and the $\mathrm{I}^{2}$ statistic exceeded $50 \%$, a random-effects model was applied, and if the $\mathrm{Q}$ test value was less than 0.1 and the $\mathrm{I}^{2}$ statistic was less than $50 \%$, a fixed-effects model was applied.

\section{Results}

\section{Search results}

We conducted a literature search following the PRISMA FLOW guidelines (Fig. 2). Of the 229 studies identified in the database, 128 remained after the removal of the duplicates. Ninety-eight studies were excluded because they did not meet the inclusion and exclusion criteria. We performed a full-text review of 30 studies to confirm whether they were suitable for our research purposes. Finally, 10 studies suitable for the systematic review, and five studies suitable for meta-analysis were selected to confirm the therapeutic effect and safety of rTMS. The detailed of exclude studies and reason is presented Additional files 1 . There were three studies with only abstracts, so we requested the original text by email, but no author responded.

\section{Characteristics of the selected studies}

Eleven studies identified the efficacy and safety of rTMS for PPD, two RCT studies [58, 59], four NRS [60-62], and five case studies [63-67]. One NRS study was excluded from the meta-analysis since the study did not report detailed outcomes. The total number of participants was 101, 84 of whom received active rTMS treatment. During pregnancy, 65 patients were treated with rTMS, and most of them were in the second and third trimesters of pregnancy. Seventeen patients were treated for postpartum depression, and two patients were treated during pregnancy and after delivery. Although 20 participants were treated with antidepressants $[60,61$, 65] along with rTMS, their antidepressant doses were stable for two to 4 weeks, and one participant was treated with clonazepam for insomnia [62]. The treatment parameters and protocols in each study were all different, which seemed to be because the protocol for TMS therapy for perinatal depression has not yet been accurately established. Twenty-two patients were stimulated to the right DLPFC $[58,60,65,66], 79$ to the left
DLPFC [59, 61-65], and the patients in one studies [65] were stimulated on both sites. The patients who were stimulated on the right DLPFC showed symptoms of anxiety and were treated with a frequency of less than 1 $\mathrm{Hz}$, which is relatively less than that used to stimulate the left DLPFC (more than $5 \mathrm{~Hz}$ ). The researchers considered the interval time and duration of stimulation to minimize side effects such as seizures and did not show any common characteristics for the other treatment parameters. The detailed are presented Tables 1,2 , and 3 .

\section{Therapeutic effects}

In the 10 studies selected for the systematic literature review, 76 patients had an average 59\% improvement in depression. Thirty-seven percent of the participants showed depression remission (depression scale rating was lowered to that of a normal person), and $66 \%$ of the participants showed a response to rTMS (depression scale score reduced more than $50 \%$ compared to before treatment). In Kim's study [58], one of the RCT studies, $45.45 \%$ of the control group responded, whereas $81 \%$ of the experimental group responded, and the remission rate also showed a significant difference of $9 \%$ or more between the experimental group and the control group. Another RCT study also showed a difference in the depression scale of about $23 \%$ between the control group and the experimental group, showing a similar treatment effect to that of antidepressants [59]. In the NRS, the response rate of 56 participants was 33\%, and the remission rate was $59 \%$. In the study by Garcia et al. [62], the depression scale scores showed that all participants achieved remission, and all except one participant responded to rTMS. The other NRS also showed treatment effects, and in the case study, all nine participants responded to rTMS. All studies showed treatment effectiveness, but treatment effectiveness declined as the study design was refined.

Evaluation of the heterogeneity of the studies for treatment effects showed a $p$-value of $<0.001$ and an $I^{2}$ statistic of 71.933. Because the $I^{2}$ statistic exceeded $50 \%$, a random-effects model was applied (Fig. 3). The effect size of rTMS for PPD had an SMD of 1.394 (95\% CI: 0.944-1.843), indicating a significant treatment effect $(\mathrm{Z}=6.079, p<0.01)$.

Figure 4 shows the sensitivity analysis performed because we thought that the treatment effect in one study [62] was measured too high. Excluding this, the heterogeneity showed a $p$-value of $<0.01$ and an $I^{2}$ statistic of 62.593, and because the $I^{2}$ value exceeded 50\%, a random-effects model was applied. The effect size of rTMS for PPD had an SMD of 1.074 (95\% CI: 0.6891.459), indicating a meaningful treatment effect $(\mathrm{Z}=$ 5.468, $p<0.01)$. The sensitivity analysis showed that the heterogeneity decreased, but the $I^{2}$ value still exceeded 


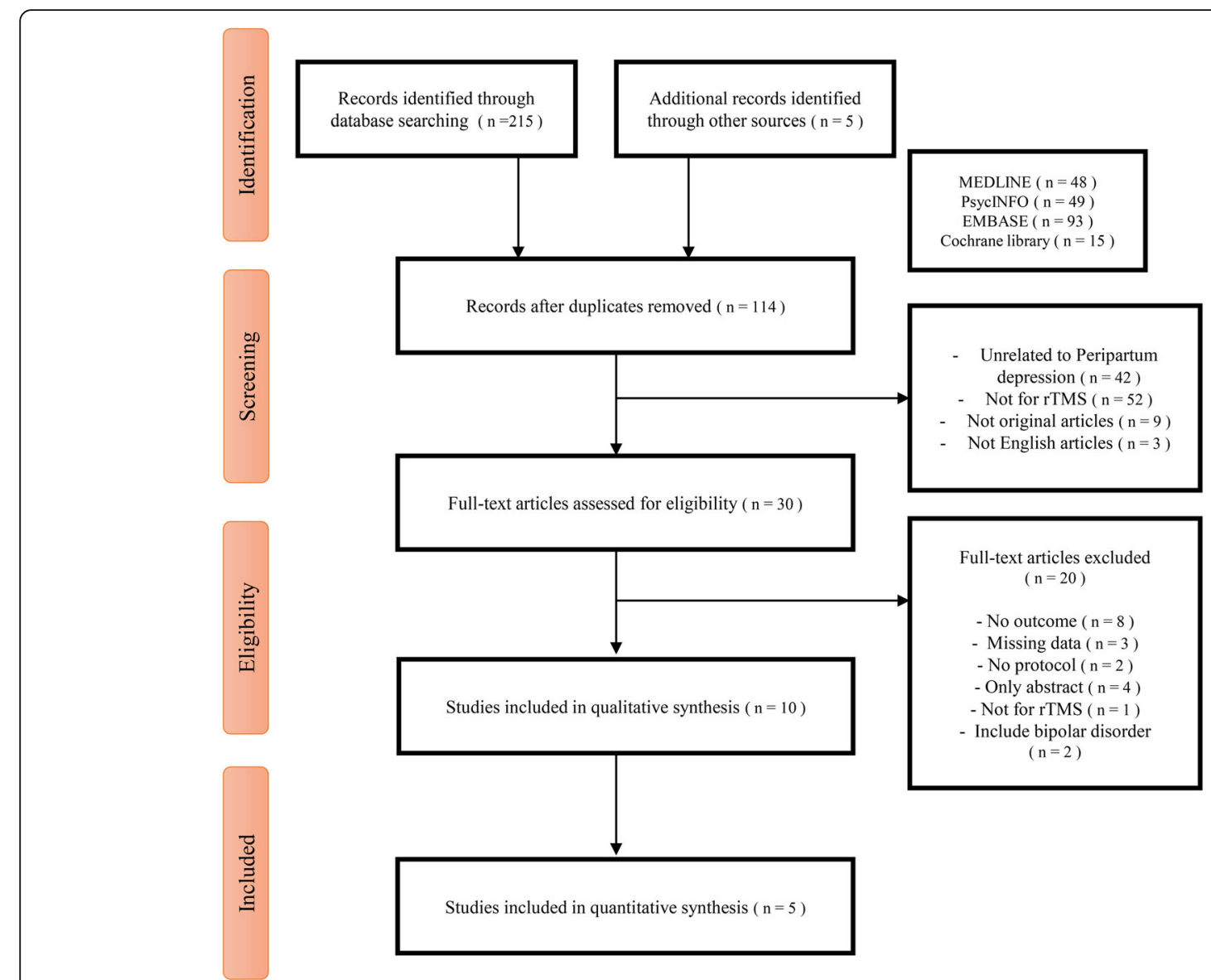

Fig. 2 Study Selection PRISMA flow diagram

$50 \%$, and the treatment effect was also slightly reduced, but the treatment effect was still significant.

\section{Safety}

In the 10 studies selected for systematic review, about $15 \%$ of the patients experienced side effects in the group receiving rTMS therapy. However, in the RCTs, there was no difference between the experimental groups and the control groups $[58,59]$, and there were minor side effects that did not worsen the patients' health, such as headache $[58,60,62,65,66]$ and pain at the stimulation site $[62,66]$. Supine hypotension syndrome was reported as an adverse event in some mothers [60]. However, this is a disorder caused by posture during treatment and can be prevented after posture correction [68]. The side effects in the infants included preterm birth, and five fetuses experienced preterm birth, but all of the fetuses were healthy. Brachial plexus injury was reported as an adverse event in one fetus, but it was caused by the large shoulder of the fetus and was not a side effect of the treatment process [58].

Evaluation of the heterogeneity of the studies for the side effects showed a $p$-value of $<0.01$ and an $I^{2}$ value of
46.631 and, because the $I^{2}$ value was less than $50 \%$, a fixed-effects model was applied (Fig. 5) The effect size of side effects had an SMD of 0.346, (95\% CI: 0.214-0.506), indicating that rTMS had an effect on the occurrence of side effects $(Z=-1.889, p=0.059)$.

\section{Risk of bias}

According to the experimental design, the RCTs were evaluated by ROB2, the NRS by ROBIN-I, and the case studies were evaluated using a methodological quality tool. We evaluated the bias according to the guidance of the tool and assessed the overall bias as a low risk of bias if all domains of bias were low risk, a high risk of bias if there were one or more high-risk domains or many suspected risks (Fig. 6). In the case of Myczkowski's study [58], the study could have selective reporting bias because the planned outcomes were selectively reported. Bias in the outcomes measurements in the NRS was evaluated as moderate [60-62] because the study design of all of the NRS was open-label, meaning that the patients knew their treatment, and the risk of bias in Garcia's study [62] was evaluated as high because there were missing data, which could have a significant impact on the 
Table 1 Characteristics of the subjects in the included studies

\begin{tabular}{|c|c|c|c|c|c|c|}
\hline Study & Study design & Subjects & Age & Gestational age & $\begin{array}{l}\text { Psychiatric } \\
\text { diagnosis }\end{array}$ & $\begin{array}{l}\text { Simultaneous } \\
\text { treatment }\end{array}$ \\
\hline \multirow[t]{2}{*}{ D. R. Kim et al., 2019 [58] } & \multirow{2}{*}{$\begin{array}{l}\text { Randomized } \\
\text { controlled trial }\end{array}$} & Active 11 & $30.13 \pm 5.78$ & $22.19 \pm 7.11$ (Weeks) & \multirow[t]{2}{*}{ MDD } & \multirow[t]{2}{*}{ Free } \\
\hline & & Sham 11 & $26.41 \pm 5.11$ & $25.62 \pm 7.61$ (Weeks) & & \\
\hline \multirow[t]{2}{*}{ Myczkowski et al., 2012 [59] } & Double-blind randomized & Active 8 & $29.63 \pm 6.37$ & $4.13 \pm 2.85$ (Month) & \multirow[t]{2}{*}{ MDD } & \multirow[t]{2}{*}{ Free } \\
\hline & controlled trial & Sham 6 & $26.67 \pm 7.15$ & $3.50 \pm 2.74$ (Month) & & \\
\hline D. R. Kim et al., 2011 [60] & $\begin{array}{l}\text { Non-randomized } \\
\text { controlled trial }\end{array}$ & 10 & $31.2 \pm 5.6$ & $25.8 \pm 5.16$ (weeks) & MDD & $\begin{array}{l}4 \text { patients treated with } \\
\text { antidepressants }\end{array}$ \\
\hline Hizli Sayar et al., 2014 [61] & $\begin{array}{l}\text { Non-randomized } \\
\text { controlled trial }\end{array}$ & 30 & $32.69 \pm 3.69$ & $14.26 \pm 8.25$ (weeks) & MDD & $\begin{array}{l}12 \text { patients treated with } \\
\text { antidepressants }\end{array}$ \\
\hline Garcia et al., 2010 [62] & $\begin{array}{l}\text { Non-randomized } \\
\text { controlled trial }\end{array}$ & 7 & $34.11 \pm 6.05$ & $\begin{array}{l}\text { After birth } \\
30 \text { days to } 1 \text { year }\end{array}$ & MDD & Free \\
\hline Zhang et al., 2010 [63] & Case report & 1 & 28 & 14 (weeks) & MDD & Free \\
\hline Tan et al., 2008 [64] & Case report & 1 & 30 & $\begin{array}{l}\text { From } 0 \text { to } \\
\text { postpartum period }\end{array}$ & MDD & Free \\
\hline \multirow[t]{2}{*}{ Ferrão et al., 2018 [65] } & \multirow[t]{2}{*}{ Case report } & 3 (Left) & $35.7 \pm 2.05$ & $6.67 \pm 3.06$ & MDD & $\begin{array}{l}2 \text { patients treated with } \\
\text { antidepressants }\end{array}$ \\
\hline & & 1 (Right) & 36 & 8 & & $\begin{array}{l}1 \text { patient treated with } \\
\text { antidepressants }\end{array}$ \\
\hline Cohen et al., 2008 [66] & Case report & 1 & 30 & Until 20 (weeks) & MDD & Free \\
\hline \multirow[t]{2}{*}{ Monika Klírová et al. [67] } & \multirow[t]{2}{*}{ Case report } & 1 (Left) & 30 & 16 & MDD & Treated with antidepressant \\
\hline & & 1 (Right) & 30 & 31 & MDD & Treated with antidepressant \\
\hline
\end{tabular}

Abbreviations: MDD Major depressive disorder

outcome. The overall evaluation of bias was moderate, but this must be considered as it can cause over or underestimation of the effect sizes. The detailed risk of bias assessment for the domains is presented in Additional files 2.

Figure 7 is a funnel plot showing the relationship between the sample size and the effect size to confirm publication bias. We visually checked whether the funnel plot was symmetrical and checked Egger's regression to determine statistically significant. Publication bias existed because the funnel plot was not symmetric and had a $p$-value of 0.01 . However, without Garcia's study [62], which had a high risk of bias, the funnel plot had a symmetrical structure and a $p$-value of 0.121 , so it can be said that there was no publication bias. In the case of safety, since there were fewer than 10 documents included, the minimum conditions for publication bias were not satisfied, and the publication bias of the side effects was not analyzed.

\section{Discussion}

The effect size of the therapeutic effect had an SMD of 1.394 (95\% CI: 0.944-1.843), which was significant for treating depression [69] and except for Garcia's study [62], in which reporting bias was suspected because of the selection reporting, the effect size SMD was 1.074, (95\% CI: 0.689-1.459), which was also a meaningful result. The studies excluded by the exclusion criteria also showed positive treatment effects of rTMS for PPD, supporting the treatment effect. In Brock's study, 14 out of
19 patients with rTMS achieved remission [70], and in Ozmut's study, eight out of 15 patients responded to rTMS [71]. Other studies also succeeded in improving the depression of patients with PPD using rTMS [72, 73]. It could be possible that the effect size was overestimated because the parameters that can affect the treatment effect, such as the site of stimulation, frequency, and interval time, were not established, and there was a risk of bias. However, even considering these points, the treatment potential was confirmed, and if a protocol becomes established, it is expected that more sophisticated effect sizes can be calculated.

The effect size of TMS side effects had an SMD of 0.346 (95\% CI: 0.214-0.506), which was significant [69]. However, the side effects of rTMS treatment on the mothers, such as headaches, discomfort, and pain in the stimulation area, were minor, and these side effects disappeared at the end of the treatment process. Some mothers experienced supine hypotension [60], but this was caused by a posture problem during treatment and could be prevented through postural correction [68].

All children born to mothers with rTMS treatment were born healthy. In one of the RCT studies that evaluated the child's health condition by appearance-pulsegrimace-activity-respiration scores, the difference between the two groups was not significant [experimental group 8.36 (1.50), control group $8.73(0.90), p=0.501$ ] [58]. There were five preterm births and one brachial 
Table $\mathbf{2}$ Characteristics of the treatments in the included studies

\begin{tabular}{|c|c|c|c|c|c|c|}
\hline Study & $\begin{array}{l}\text { Motor } \\
\text { threshold }\end{array}$ & $\begin{array}{l}\text { Site of } \\
\text { stimulation }\end{array}$ & Frequency & $\begin{array}{l}\text { Number of } \\
\text { pulses }\end{array}$ & $\begin{array}{l}\text { Inter-event } \\
\text { interval }\end{array}$ & Number of Sessions \\
\hline D. R. Kim et al., 2019 [58] & $100 \%$ & Right DLPFC & $1-\mathrm{Hz}$ & 900 & $\begin{array}{l}60 \text { s on } \\
60 \text { s off }\end{array}$ & 20 \\
\hline Myczkowski et al., 2012 [59] & $120 \%$ & Left DLPFC & $5-\mathrm{Hz}$ & 1250 & $\begin{array}{l}10 \mathrm{~s} \text { on } \\
20 \mathrm{~s} \text { off }\end{array}$ & 25 \\
\hline D. R. Kim et al., 2011 [60] & $100 \%$ & Right DLPFC & $1-\mathrm{Hz}$ & 300 & $\begin{array}{l}60 \text { s on } \\
60 \text { s off }\end{array}$ & 20 \\
\hline Hizli Sayar et al., 2014 [61] & $100 \%$ & Left DLPFC & $25-\mathrm{Hz}$ & 1000 & $\begin{array}{l}2 \mathrm{~s} \text { on } \\
30 \mathrm{~s} \text { off }\end{array}$ & 18 \\
\hline Garcia et al., 2010 [62] & $120 \%$ & Left DLPFC & $10-\mathrm{Hz}$ & 150 & $\begin{array}{l}4 s \text { on } \\
26 s \text { off }\end{array}$ & 20 \\
\hline Zhang et al., 2010 [63] & $90 \%$ & Left DLPFC & $1-\mathrm{Hz}$ & 1200 & $20 \mathrm{~s}$ off & 42 \\
\hline Tan et al., 2008 [64] & $110 \%$ & Left DLPFC & $25-\mathrm{Hz}$ & 1000 & $\begin{array}{l}2 \mathrm{~s} \text { on } \\
28 \mathrm{~s} \text { off }\end{array}$ & 77 \\
\hline \multirow[t]{2}{*}{ Ferrão et al., 2018 [65] } & $120 \%$ & Left DLPFC & $10-\mathrm{Hz}$ & 3000 & * & 42.67 \\
\hline & & Right DLPRC & $1-\mathrm{Hz}$ & 1800 & & 20 \\
\hline Cohen et al., 2008 [66] & $110 \%$ & Right DLPFC & $1-\mathrm{Hz}$ & 1600 & * & 1 \\
\hline \multirow[t]{2}{*}{ Monika Klírová et al. [67] } & $100 \%$ & Left DLPFC & $20-\mathrm{Hz}$ & 2000 & $\begin{array}{l}2 \mathrm{~s} \text { on } \\
30 \mathrm{~s} \text { off }\end{array}$ & 15 \\
\hline & & Right DLPRC & $1-\mathrm{Hz}$ & 300 & $\begin{array}{l}60 \text { s on } \\
60 \text { s off }\end{array}$ & 15 \\
\hline
\end{tabular}

Abbreviations: DLPFC Dorsolateral prefrontal cortex; s Seconds

plexus injury among the fetuses. Although 5\% (5) of the study participants experienced preterm birth, two of these had already been warned of the risk of preterm birth by a biomedical test. Considering that the average proportion of women who undergo preterm birth worldwide is $11 \%$ [74], it is unlikely that a causal relationship exists between rTMS and preterm birth. However, further research on this is needed. Brachial plexus injury was reported as a side effect in one newborn, but it was not related to rTMS treatment [58], and there were no other side effects in the infants. One study that checked the child of a mother treated with rTMS reported that the exposure during pregnancy did not affect the cognitive or motor development of the child [75]. High

Table 3 Characteristics of the outcomes in the included studies

\begin{tabular}{|c|c|c|c|c|c|c|c|}
\hline Study & Instrument & Pre-TMS**** & Post-TMS & Remission & Response & Side effects (mother) & Infants \\
\hline \multirow[t]{2}{*}{ D. R. Kim et al., 2019 [58] } & HDRS-17 & $23.18 \pm 3.54$ & $9.27 \pm 6.05$ & 3 & 9 & $1(10 \%)$ & $4(36 \%)$ \\
\hline & & $22.27 \pm 2.65$ & $13.18 \pm 8.00$ & 2 & 5 & & \\
\hline \multirow[t]{2}{*}{ Myczkowski et al., 2012 [59] } & HDRS-17 & $29.13 \pm 5.64$ & $18.50 \pm 9.83$ & * & * & $2(25 \%)$ & $0(0 \%)$ \\
\hline & & $26.67 \pm 5.68$ & $24.83 \pm 7.60$ & & & & \\
\hline D. R. Kim et al., 2011 [60] & HDRS-17 & $24.4 \pm 5.6$ & $9.7 \pm 6.1$ & 3 & 7 & $4(40 \%)$ & $0(0 \%)$ \\
\hline Hizli Sayar et al., 2014 [61] & HDRS-17 & $26.67 \pm 5.58$ & $13.03 \pm 6.93$ & 6 & 12 & $0(0 \%)$ & $0(0 \%)$ \\
\hline Garcia et al., 2010 [62] & HDRS-24 & $22.67 \pm 6.44$ & $2.14 \pm 3.19$ & 8 & 9 & $2(29 \%)$ & $0(0 \%)$ \\
\hline Zhang et al., 2010 [63] & HDRS-24 & 35 & 8 & 1 & 1 & $0(0 \%)$ & $0(0 \%)$ \\
\hline $\begin{array}{l}\text { Tan et al., } \\
2008 \text { [64] }\end{array}$ & HDRS-17 & 38 & 4 & 1 & 1 & $0(0 \%)$ & $0(0 \%)$ \\
\hline \multirow[t]{2}{*}{ Ferrão et al., 2018 [65] } & HDRS-21 & $24.33 \pm 5.24$ & $7.33 \pm 4.03$ & 2 & 3 & $2(66 \%)$ & $1(25 \%)$ \\
\hline & & 12 & 6 & 1 & 1 & $1(100 \%)$ & \\
\hline Cohen et al., 2008 [66] & HDRS-17 & 18 & 6 & 1 & 1 & $0(0 \%)$ & $0(0 \%)$ \\
\hline \multirow[t]{2}{*}{ Monika Klírová et al., 2008 [67] } & MADRS & 33 & 2 & * & * & $0(0 \%)$ & $0(0 \%)$ \\
\hline & $\mathrm{BDI}$ & 29 & 12 & * & * & & \\
\hline
\end{tabular}




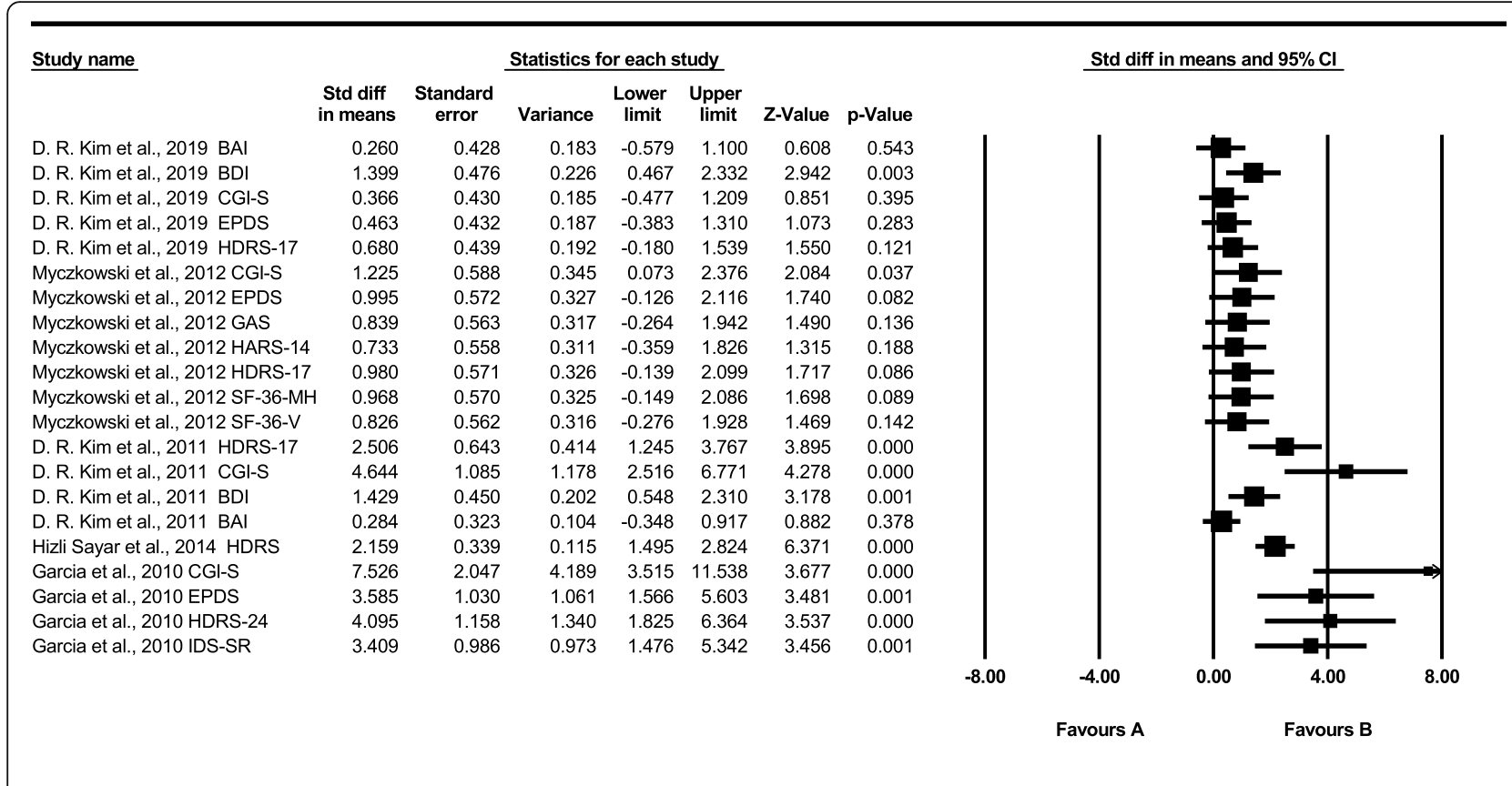

\section{Meta Analysis}

Fig. 3 Forest plot of therapeutic effects. Abbreviations: BAl: Beck Anxiety Inventory; BDI: Beck Depression Inventory; CGI-S: Clinical Global. Impression Scale; EPDS: Edinburgh Postnatal Depression Scale; HDRS: Hamilton Depression. Rating Scale; GAS, Global Assessment Scale; SF-36-V and SF-36-MH: 36-item Quality of Life. Health Survey, Vitality, and Mental Health scores; IDS-SR: Inventory of

Depressive. Symptomatology-Self-Report

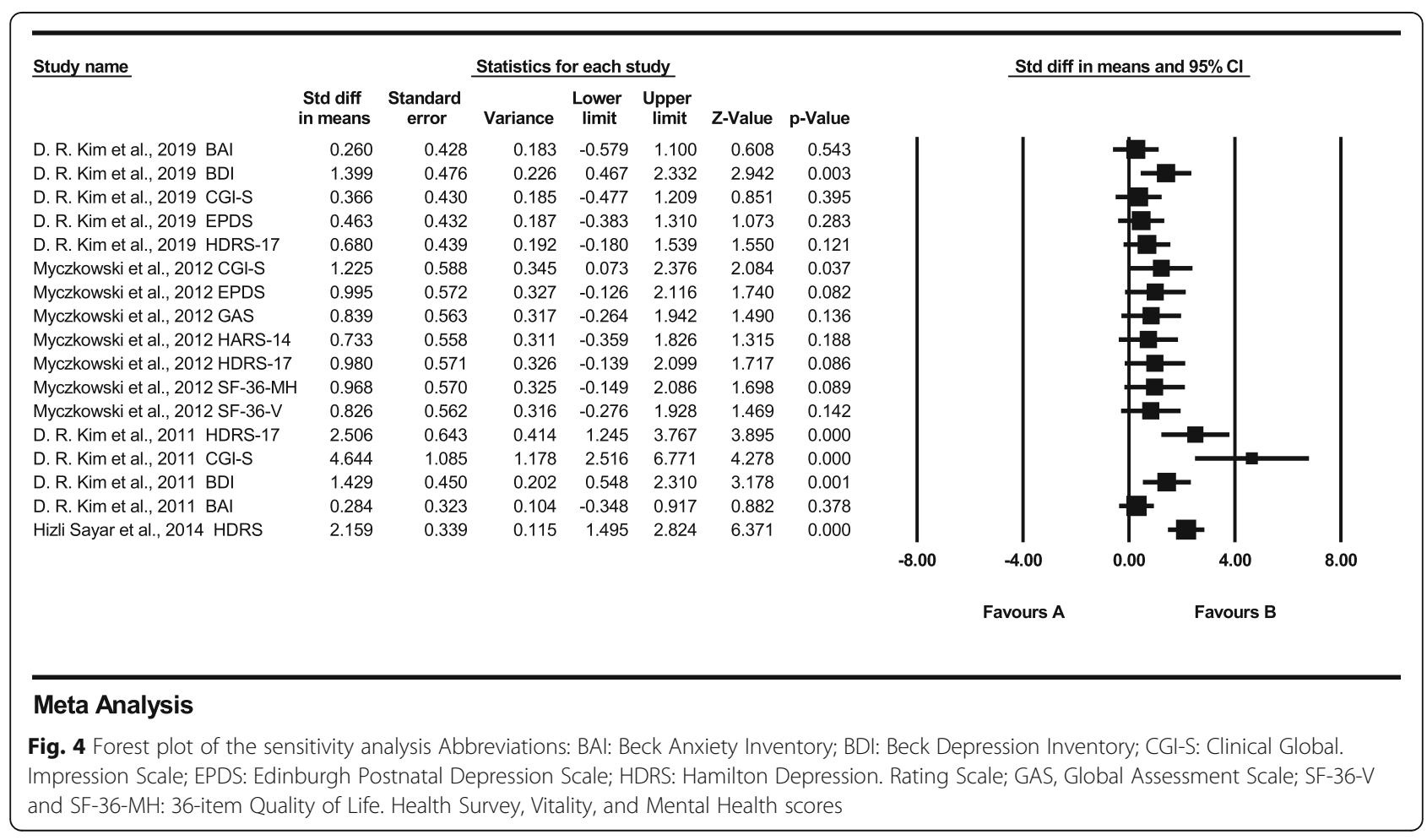




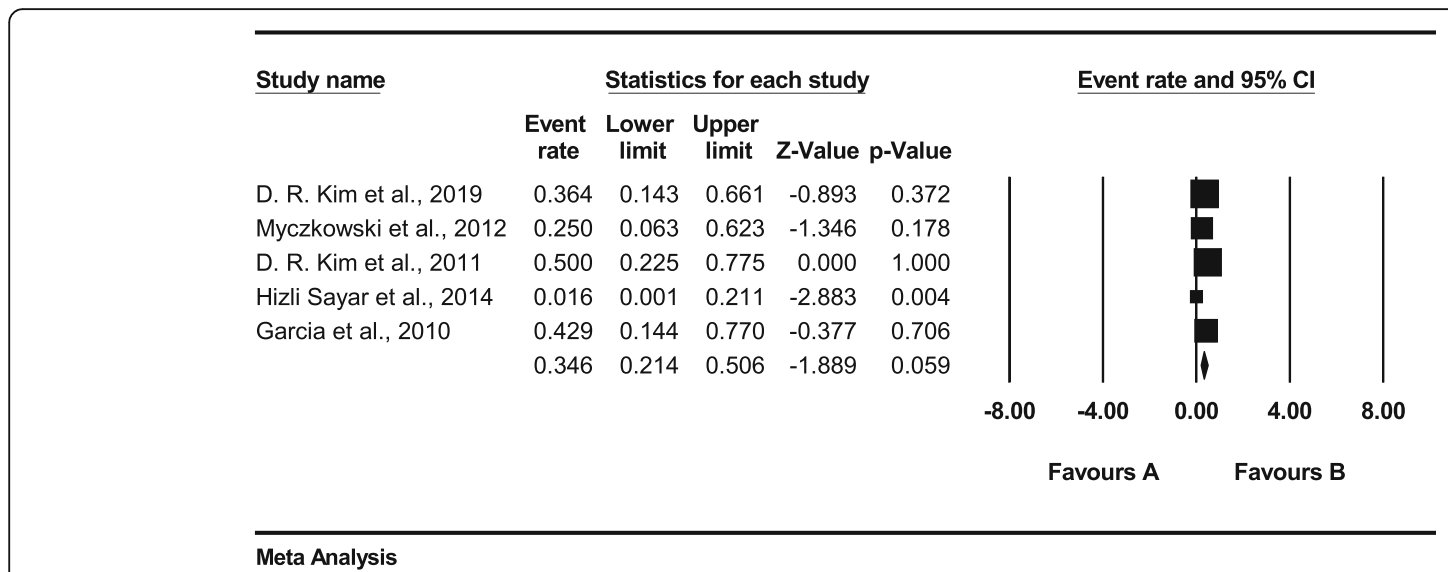

Fig. 5 Forest plot of the side effects

frequencies above $40 \mathrm{~Hz}$ affect the lungs and immune system of the fetus [76, 77], and the maximum electromagnetic field applicable to the fetus is $800 \mathrm{mv} / \mathrm{m}$ [78]. However, the frequency used in rTMS treatment is generally $1-25 \mathrm{~Hz}$, and the scale of the electromagnetic field is $100 \mathrm{mv} / \mathrm{m}$ [79]. Nevertheless, additional research should be conducted because there are many aspects not yet researched.

Mothers do not prefer the current treatment for peripartum depression. They are not willing to take antidepressants because they are concerned not only about the side effects that they will suffer but also the side effects to the fetus $[80,81]$ Besides, $2.5 \%$ of mothers suffer from treatment-resistant depression and have to choose a different treatment method [82]. In one survey on depression treatments, only $1.2 \%$ of the population accepted ECT treatment [83]. Although the acceptance rate of rTMS was also low, when knowledge about the treatment was shared, the acceptance rate increased by more than $50 \%$, showing the possibility as a treatment method for PPD [84].

From the side of economic efficiency, rTMS may be a good alternative for treating PPD. For example, rTMS might save \$112 per quality-adjusted life years (QALY) compared to antidepressants [85] and might save $\$ 8515$ per year compared to ECTs [86]. rTMS could reduce anxiety about the cost, which was one of the risk factors that had the most significant impact on pregnant women [87]. Consequently, the socioeconomic costs of peripartum depression might be reduced.

\section{Limitation and future study direction}

Regarding the limitations of the meta-analysis, our results showed high heterogeneity, and the reason may be heterogeneity due to methodological diversity because the parameters of rTMS varied from study to study, or heterogeneity due to coincidence because the analysis was conducted with small sample-sized studies. However, because the parameters vary according to the patient's situation (e.g., the stimulation site changes according to symptoms and the frequency changes according to the stimulation site), it should be judged as clinical heterogeneity. The lack of patients and studies might also constrain our results. Thus, the effects of rTMS on PPD and should be interpreted with caution. Future research should focus on the effects in the

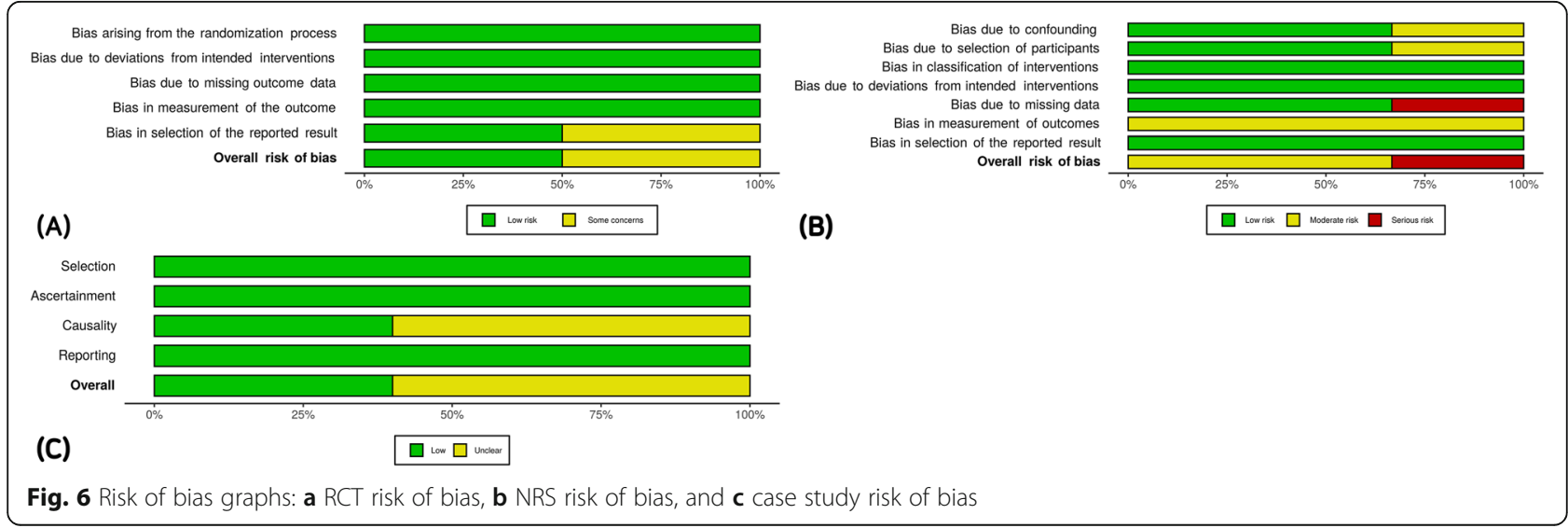




\section{Funnel Plot of Standard Error by Std diff in means}

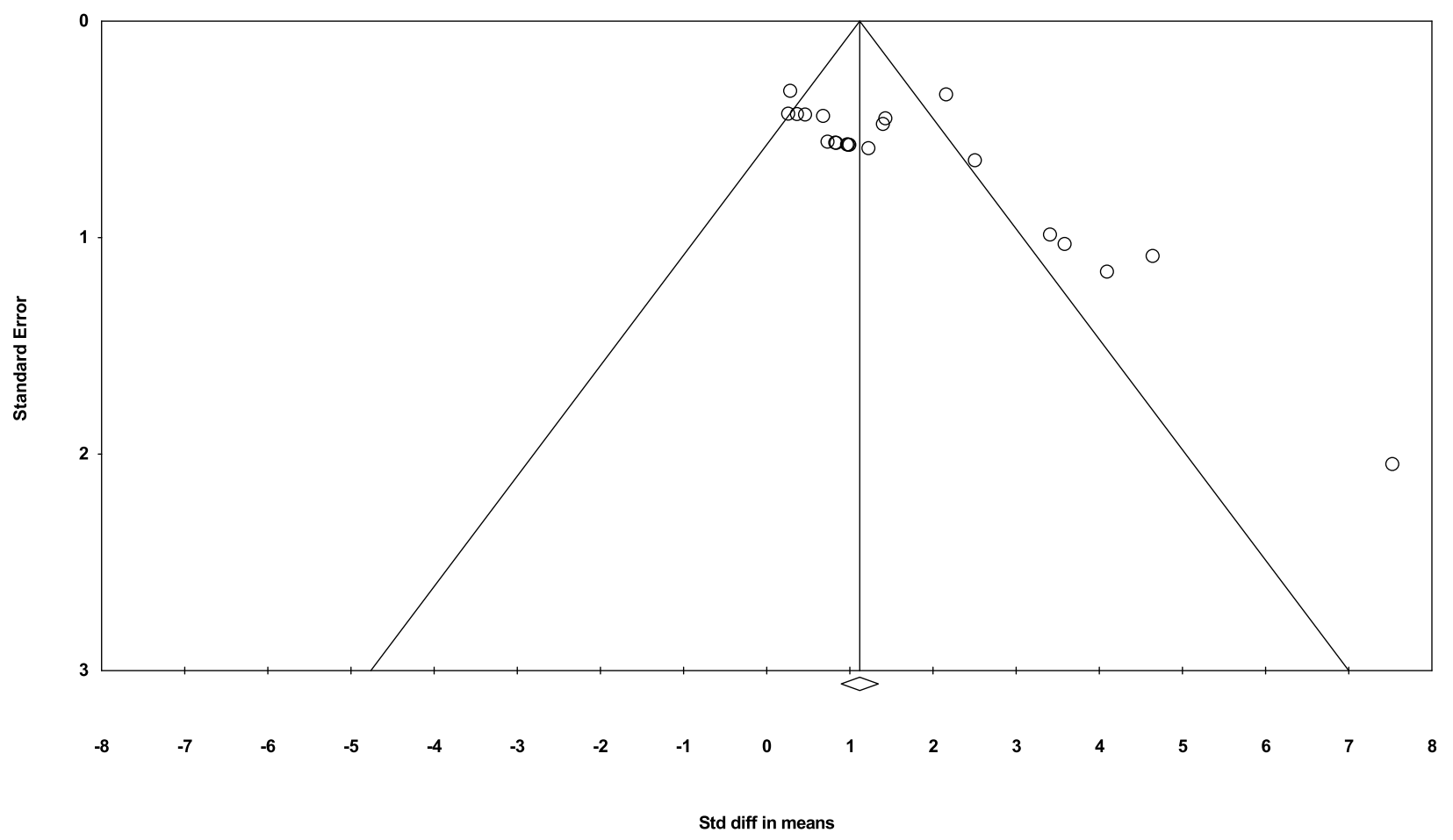

Fig. 7 Funnel plot

prenatal and infancy periods and establish parameters for rTMS, such as the site stimulation or frequency.

\section{Conclusions}

We collected data from existing documents and identified 10 studies that were suitable for a systematic review, of which five are eligible for meta-analysis. According to the analysis of the included studies, the therapeutic effect size of rTMS for PPD showed an SMD of 1.394 (95\% CI: 0.944-1.843), and the sensitivity analysis showed an $\mathrm{SMD}=1.074 \quad(95 \% \mathrm{CI}$ : 0.689-1.459), which is a significant effect, but this effect size could be overestimated because more than $50 \%$ of the studies were NRS, and some studies were at risk of bias Nonetheless, rTMS seems to have potential as a treatment for peripartum depression. The side effects of rTMS for PPD had an SMD of 0.346 (95\% CI: 0.214-0.506), which is meaningful. However, there were no serious side effects to the mothers or fetuses. From a variety of perspectives, the treatment of PPD using rTMS could be considered an alternative treatment to avoid exposure of the fetus to drugs and the severe side effects of ECT. Further research is required to increase the confidence in these results.

\section{Supplementary Information}

The online version contains supplementary material available at https://doi. org/10.1186/s12884-021-03600-3.

Additional file 1: Appendix 1. Excluded literature and the reason.

Additional file 2: Appendix 2. Risk assessment of selected literature.

\section{Abbreviations}

PPD: Peripartum depression; MDD: Major depressive disorder;

ECT: Electroconvulsive therapy; MAO: Monoamine oxidase; rTMS: Repeated transcranial magnetic stimulation; DLPFC: Dorsolateral prefrontal cortex; RCT: Randomized controlled trial; NRS: Non-randomized studies; DSM-

5: Diagnostic and Statistical Manual of Mental Disorders-5; HDRS: Hamilton Depression Rating Scale; ROB2: Risk of bias 2; ROBINS-I: The Risk of Bias Assessment tool for Nonrandomized Studies; SMD: Standardized Mean Deviation; Cl: Confidence interval; MARDS: Montgomery-Åsberg Depression Rating Scale; BDI: Beck Depression Inventory:; EPDS: Edinburgh Postnatal Depression Scale; QALY: Quality adjusted life year; CGI-S: Clinical Global impression scale; GAS: Global Assessment Scale; SF-36-V: 36-item Quality of Life Health Survey Vitality scores; SF-36-MH: 36-item Quality of Life Health Survey Mental Health scores

\section{Acknowledgements}

We would like to thank the Korea Health Industry Development Institute (KHIDI) for supporting the training program for advanced medical device industry professionals.

\section{Authors' contributions}

HJ: Conceive the project, search strategy, screening literature, data extraction, bias evaluation, data analysis, and drafting the manuscript and revising JY:

Study design, screening literature, bias evaluation, data analysis, drafting the 
manuscript, and revising the manuscript and SMK supervised the entire procedures and helped to draft the manuscript. All authors read and approved the final manuscript.

\section{Funding}

No funding was obtained for this study.

\section{Availability of data and materials}

No data or materials were generated for this narrative review.

\section{Ethics approval and consent to participate}

Not applicable.

\section{Consent for publication}

Not applicable.

\section{Competing interests}

The authors declare that they have no competing interest.

Received: 4 November 2020 Accepted: 28 January 2021 Published online: 09 February 2021

\section{References}

1. Association D-AP: Diagnostic and statistical manual of mental disorders. 2013.

2. Bauer A, Knapp M, Parsonage M. Lifetime costs of perinatal anxiety and depression. J Affect Disord. 2016;192:83-90.

3. Schiller CE, Meltzer-Brody S, Rubinow DR. The role of reproductive hormones in postpartum depression. CNS spectrums. 2015;20(1):48-59.

4. Rubio DM, Kraemer KL, Farrell MH, Day NL. Factors associated with alcohol use, depression, and their co-occurrence during pregnancy. Alcohol Clin Exp Res. 2008;32(9):1543-51.

5. Chang HY, Keyes KM, Lee KS, Choi IA, Kim SJ, Kim KW, Shin YH, Ahn KM, Hong SJ, Shin YJ. Prenatal maternal depression is associated with low birth weight through shorter gestational age in term infants in Korea. Early Hum Dev. 2014;90(1):15-20.

6. Liu C, Cnattingius S, Bergstrom M, Ostberg V, Hjern A. Prenatal parental depression and preterm birth: a national cohort study. BJOG. 2016;123(12): 1973-82.

7. Accortt EE, Cheadle ACD, Dunkel Schetter C. Prenatal depression and adverse birth outcomes: an updated systematic review. Matern Child Health J. 2015;19(6):1306-37.

8. Field T. Prenatal depression risk factors, developmental effects and interventions: A review. J Pregnancy Child Health. 2017;4(1):301.

9. Wichman CL, Stern TA. Diagnosing and Treating Depression During Pregnancy. Prim Care Companion CNS Disord. 2015;17(2). https://doi.org/10. 4088/PCC.4015f01776.

10. Calaway K, Coshal S, Jones K, Coverdale J, Livingston R. A systematic review of the safety of electroconvulsive therapy use during the first trimester of pregnancy. J ECT. 2016;32(4):230-5.

11. Eke AC, Saccone G, Berghella V. Selective serotonin reuptake inhibitor (SSRI) use during pregnancy and risk of preterm birth: a systematic review and meta-analysis. BJOG. 2016;123(12):1900-7.

12. Leiknes KA, Cooke MJ, Jarosch-von Schweder L, Harboe I, Hoie B. Electroconvulsive therapy during pregnancy: a systematic review of case studies. Arch Womens Ment Health. 2015;18(1):1-39.

13. Prady SL, Hanlon I, Fraser LK, Mikocka-Walus A. A systematic review of maternal antidepressant use in pregnancy and short- and long-term offspring's outcomes. Arch Womens Ment Health. 2018;21(2):127-40.

14. Richelson E. Pharmacology of antidepressants. Mayo Clin Proc. 2001;76(5): $511-27$

15. Stahl SM. Basic psychopharmacology of antidepressants: Part 1. Antidepressants have seven distinct mechanisms of action. J Clin Psychiatry. 1998;59(Suppl 4):5-14.

16. Hendrick V, Stowe ZN, Altshuler LL, Hwang S, Lee E, Haynes D. Placental passage of antidepressant medications. Am J Psychiatr. 2003;160(5):993-6.

17. Nikfar S, Rahimi R, Hendoiee N, Abdollahi M. Increasing the risk of spontaneous abortion and major malformations in newborns following use of serotonin reuptake inhibitors during pregnancy: a systematic review and updated meta-analysis. Daru. 2012;20(1):75.
18. Rahimi R, Nikfar S, Abdollahi M. Pregnancy outcomes following exposure to serotonin reuptake inhibitors: a meta-analysis of clinical trials. Reprod Toxicol. 2006;22(4):571-5.

19. Julsgaard M, Christensen LA, Gibson PR, Gearry RB, Fallingborg J, Hvas CL, Bibby BM, Uldbjerg N, Connell WR, Rosella O, et al. Concentrations of Adalimumab and infliximab in mothers and newborns, and effects on infection. Gastroenterology. 2016;151(1):110-9.

20. Huang $\mathrm{H}$, Coleman S, Bridge JA, Yonkers K, Katon W. A meta-analysis of the relationship between antidepressant use in pregnancy and the risk of preterm birth and low birth weight. Gen Hosp Psychiatry. 2014;36(1):13-8.

21. Boukhris T, Sheehy O, Mottron L, Berard A. Antidepressant use during pregnancy and the risk of autism Spectrum disorder in children. JAMA Pediatr. 2016:170(2):117-24.

22. Brown AS, Gyllenberg D, Malm H, McKeague IW, Hinkka-Yli-Salomaki S, Artama M, Gissler M, Cheslack-Postava K, Weissman MM, Gingrich JA, et al. Association of Selective Serotonin Reuptake Inhibitor Exposure during Pregnancy with Speech, scholastic, and motor disorders in offspring. JAMA Psychiatry. 2016;73(11):1163-70.

23. Huybrechts KF, Palmsten K, Avorn J, Cohen LS, Holmes LB, Franklin JM, Mogun $H$, Levin R, Kowal M, Setoguchi S. Antidepressant use in pregnancy and the risk of cardiac defects. New Engl J Med. 2014;370(25):2397-407.

24. Huybrechts KF, Bateman BT, Palmsten K, Desai RJ, Patorno E, Gopalakrishnan C, Levin R, Mogun H, Hernandez-Diaz S. Antidepressant use late in pregnancy and risk of persistent pulmonary hypertension of the newborn. JAMA. 2015;313(21):2142-51.

25. Berle JØ, Spigset O. Antidepressant use during breastfeeding. Curr Womens Health Rev. 2011;7(1):28-34.

26. Davanzo R, Copertino M, De Cunto A, Minen F, Amaddeo A. Antidepressant drugs and breastfeeding: a review of the literature. Breastfeed Med. 2011; 6(2):89-98.

27. Schmidt K, Olesen OV, Jensen PN. Citalopram and breast-feeding: serum concentration and side effects in the infant. Biol Psychiatry. 2000;47(2):164-5.

28. Lee A, Woo J, Ito S. Frequency of infant adverse events that are associated with citalopram use during breast-feeding. Am J Obstet Gynecol. 2004; 190(1):218-21

29. Singh A, Kar SK. How electroconvulsive therapy works?: understanding the neurobiological mechanisms. Clin Psychopharmacol Neurosci. 2017;15(3): 210-21.

30. Balki M, Castro C, Ananthanarayan C. Status epilepticus after electroconvulsive therapy in a pregnant patient. Int J Obstet Anesth. 2006; 15(4):325-8.

31. Pesiridou A, Baquero G, Cristancho P, Wakil L, Altinay M, Kim D, O'Reardon JP. A case of delayed onset of threatened premature labor in association with electroconvulsive therapy in the third trimester of pregnancy. J ECT. 2010;26(3):228-30

32. Bozkurt AKT, Isintas M, Ozmenler NK, Ozsahin A, Yanarates O. Acute and maintenance electroconvulsive therapy for treatment of psychotic depression in a pregnant patient. J ECT. 2007;23(3):185-7.

33. Lovas A, Almos PZ, Peto Z, Must A, Horvath S. Anesthesia for electroconvulsive therapy in early pregnancy. J ECT. 2011;27(4):328-30.

34. Koren G, Nordeng H. Antidepressant use during pregnancy: the benefit-risk ratio. Am J Obstet Gynecol. 2012;207(3):157-63.

35. Saatcioglu O, Tomruk NB. The use of electroconvulsive therapy in pregnancy: a review. Israel J Psychiatry Related Sci. 2011;48(1):6.

36. Health Quality O. Repetitive Transcranial magnetic stimulation for treatment-resistant depression: a systematic review and Meta-analysis of randomized controlled trials. Ontario Health Technol Assess Series. 2016; 16(5):1-66.

37. George MS, Taylor JJ, Short EB. The expanding evidence base for rTMS treatment of depression. Curr Opin Psychiatry. 2013;26(1):13-8.

38. VanDerwerker CJ, Ross RE, Stimpson KH, Embry AE, Aaron SE, Cence B, George MS, Gregory CM. Combining therapeutic approaches: rTMS and aerobic exercise in post-stroke depression: a case series. Top Stroke Rehabil. 2018;25(1):61-7.

39. Krepel N, Rush AJ, Iseger TA, Sack AT, Arns M. Can psychological features predict antidepressant response to rTMS? A Discovery-Replication approach. Psychol Med. 2017;50(2):264-72.

40. Chang D, Zhang J, Peng W, Shen Z, Gao X, Du Y, Ge Q, Song D, Shang Y, Wang Z. Smoking cessation with $20 \mathrm{~Hz}$ repetitive Transcranial magnetic stimulation (rTMS) applied to two brain regions: a pilot study. Front Hum Neurosci. 2018;12:344. 
41. Voigt J, Carpenter L, Leuchter A. A systematic literature review of the clinical efficacy of repetitive transcranial magnetic stimulation (rTMS) in nontreatment resistant patients with major depressive disorder. BMC Psychiatry. 2019;19(1):13.

42. McNamara B, Ray J, Arthurs O, Boniface S. Transcranial magnetic stimulation for depression and other psychiatric disorders. Psychol Med. 2001;31(7): 1141-6.

43. KOZEL FA, GEORGE MS. Meta-analysis of left prefrontal repetitive transcranial magnetic stimulation (rTMS) to treat depression. J Psychiatric Pract. 2002; 8(5):270-5.

44. Burt T, Lisanby SH, Sackeim HA. Neuropsychiatric applications of transcranial magnetic stimulation: a meta analysis. Int J Neuropsychopharmacol. 2002; 5(1):73-103.

45. Konstantinou GN, Vigod SN, Mehta S, Daskalakis ZJ, Blumberger DM. A systematic review of non-invasive neurostimulation for the treatment of depression during pregnancy. J Affect Disord. 2020;272:259-68.

46. Ganho-Ávila A, Poleszczyk A, Mohamed MMA, Osório A. Efficacy of rTMS in decreasing postnatal depression symptoms: a systematic review. Psychiatry Res. 2019;279:315-22.

47. Felipe RM, Ferrão YA. Transcranial magnetic stimulation for treatment of major depression during pregnancy: a review. Trends Psychiatry Psychotherapy. 2016:38:190-7.

48. Cole J, Bright K, Gagnon L, McGirr A. A systematic review of the safety and effectiveness of repetitive transcranial magnetic stimulation in the treatment of peripartum depression. J Psychiatr Res. 2019;115:142-50.

49. Moher D, Shamseer L, Clarke M, Ghersi D, Liberati A, Petticrew M, Shekelle P, Stewart LA, Group P-P. Preferred reporting items for systematic review and meta-analysis protocols (PRISMA-P) 2015 statement. Syst Rev. 2015;4(1):1.

50. Akl E, Altman D, Aluko P, Askie L, Beaton D, Berlin J, Bhaumik B, Bingham C, Boers $\mathrm{M}$, Booth A et al: Cochrane handbook for systematic reviews of interventions; 2019.

51. Spronk D, Arns M, Fitzgerald PB. Repetitive transcranial magnetic stimulation in depression: protocols, mechanisms, and new developments. In: Neurofeedback and neuromodulation techniques and applications. edn. Elsevier; 2011. p. 257-291. https://www.sciencedirect.com/science/article/pii/ B978012382235200010X

52. Higgins JP, Sterne JA, Savovic J, Page MJ, Hróbjartsson A, Boutron I, Reeves $B$, Eldridge $S$. A revised tool for assessing risk of bias in randomized trials. Cochrane Database Syst Rev. 2016;10(Suppl 1):29-31.

53. Sterne JA, Hernán MA, Reeves BC, Savović J, Berkman ND, Viswanathan M, Henry D, Altman DG, Ansari MT, Boutron I, et al. ROBINS-I: a tool for assessing risk of bias in non-randomised studies of interventions. BMJ. 2016; 355:i4919.

54. Murad MH, Sultan S, Haffar S, Bazerbachi F. Methodological quality and synthesis of case series and case reports. BMJ Evid Based Med. 2018;23(2): 60-3.

55. Carey JC. Significance of case reports in the advancement of medical scientific knowledge. Am J Med Genet A. 2006;140(19):2131-4.

56. Higgins JPT, Thompson SG, Deeks JJ, Altman DG. Measuring inconsistency in meta-analyses. BMJ. 2003;327(7414):557-60.

57. Becker BJ. Synthesizing standardized mean-change measures. Br J Math Stat Psychol. 1988;41(2):257-78.

58. Kim DR, Wang E, McGeehan B, Snell J, Ewing G, lannelli C, O'Reardon JP, Sammel MD, Epperson CN. Randomized controlled trial of transcranial magnetic stimulation in pregnant women with major depressive disorder. Brain Stimul. 2019;12(1):96-102.

59. Myczkowski ML, Dias AM, Luvisotto T, Arnaut D, Bellini BB, Mansur CG, Renno J, Tortella G, Ribeiro PL, Marcolin MA. Effects of repetitive transcranial magnetic stimulation on clinical, social, and cognitive performance in postpartum depression. Neuropsychiatr Dis Treat. 2012;8:491-500.

60. Kim DR, Epperson N, Pare E, Gonzalez JM, Parry S, Thase ME, Cristancho P, Sammel MD, O'Reardon JP. An open label pilot study of transcranial magnetic stimulation for pregnant women with major depressive disorder J Women's Health (Larchmt). 2011;20(2):255-61.

61. Hizli Sayar G, Ozten E, Tufan E, Cerit C, Kagan G, Dilbaz N, Tarhan N. Transcranial magnetic stimulation during pregnancy. Arch Womens Ment Health. 2014;17(4):311-5.

62. Garcia KS, Flynn P, Pierce KJ, Caudle M. Repetitive transcranial magnetic stimulation treats postpartum depression. Brain Stimul. 2010;3(1):36-41.

63. Zhang $X$, Liu K, Sun J, Zheng Z. Safety and feasibility of repetitive transcranial magnetic stimulation (rTMS) as a treatment for major depression during pregnancy. Arch Womens Ment Health. 2010;13(4): 369-70.

64. Tan O, Tarhan N, Coban A, Baripoglu SK, Guducu F, Izgi HB, Hizli G, Ates O, Bulut $H$. Antidepressant effect of 58 sessions of rTMS in a pregnant woman with recurrent major depressive disorder: a case report. Prim Care Companion J Clin Psychiatry. 2008;10(1):69-71.

65. Ferrao YA, RdMFd S. Repetitive transcranial magnetic stimulation for the treatment of major depression during pregnancy. Braz J Psychiatry. 2018; 40(1):227-8.

66. Cohen RB, Ferreira MS, Ferreira MJ, Fregni F. Use of repetitive transcranial magnetic stimulation for the management of bipolar disorder during the postpartum period. Brain Stimulation. 2008;1(3):224-6.

67. Klírová M, Novak T, Kopecek M, Mohr P, Strunzova V. Repetitive transcranial magnetic stimulation (rTMS) in major depressive episode during pregnancy. Neuro Endocrinol Letters. 2008;29:69-70.

68. Kim DR, Wang E. Prevention of supine hypotensive syndrome in pregnant women treated with transcranial magnetic stimulation. Psychiatry Res. 2014; 218(1-2):247-8

69. Cohen J. Statistical power analysis for the behavioral sciences: academic press; 2013.

70. Brock DG, Demitrack MA, Groom P, Holbert R, Rado JT, Gross PK, Goethe JW, Schrodt GR, Weeks HR. Effectiveness of NeuroStar transcranial magnetic stimulation (TMS) in patients with major depressive disorder with postpartum onset. Brain Stimul Basic Transl Clin Res Neuromodul. 2016;9(5): e7.

71. Ozmut O, Balibey H, Yilan Y, Algul A, Ebrinc S, Cetin M, Tutuncu R, Ates A, Basoglu C. Repetitive transcranial magnetic stimulation for the treatment of depression during pregnancy and postpartum period. Bull Clin Psychopharmacol. 2015;25(1):S203-4.

72. Stultz DJ, Thistlethwaite D, Voltin R, Osburn S, Walton R, Burns T. Bipolar, depressed, and pregnant - transcranial magnetic stimulation as a treatment alternative. Brain Stimul Basic Transl Clin Res Neuromodul. 2018:11(6):e15.

73. Xiong W, Lopez R, Cristancho P. Transcranial magnetic stimulation in the treatment of peripartum bipolar depression: a case report. Rev Bras Psiquiatria. 2018;40(3):344-5.

74. Walani SR. Global burden of preterm birth. Int J Gynecol Obstet. 2020;150(1): 31-3.

75. Eryılmaz G, Sayar GH, Özten E, Gül IG, Yorbik Ö, Işiten N, Bağcı E. Follow-up study of children whose mothers were treated with transcranial magnetic stimulation during pregnancy: preliminary results. Neuromodulation. 2015; 18(4):255-60.

76. Bracken MB, Belanger K, Cookson WO, Triche E, Christiani DC, Leaderer BP. Genetic and perinatal risk factors for asthma onset and severity: a review and theoretical analysis. Epidemiol Rev. 2002;24(2):176-89.

77. Li DK, Chen H, Odouli R. Maternal exposure to magnetic fields during pregnancy in relation to the risk of asthma in offspring. Arch Pediatr Adolesc Med. 2011;165(10):945-50.

78. Allen CH, Kluger BM, Buard I. Safety of Transcranial magnetic stimulation in children: a systematic review of the literature. Pediatr Neurol. 2017;68:3-17.

79. Yanamadala J, Noetscher GM, Makarov SN, Pascual-Leone A. Estimates of peak electric fields induced by Transcranial magnetic stimulation in pregnant women as patients using an FEM full-body model. In: 2017 39th Annual International Conference of the IEEE Engineering in Medicine and Biology Society (EMBC): 11-15 July 2017 2017; 2017. p. 1441-4.

80. O'Mahen HA, Flynn HA. Preferences and perceived barriers to treatment for depression during the perinatal period. J Women's Health. 2008;17(8):1301-9.

81. Goodman JH. Women's attitudes, preferences, and perceived barriers to treatment for perinatal depression. Birth. 2009;36(1):60-9.

82. Cepeda MS, Kern DM, Nicholson S. Treatment resistant depression in women with peripartum depression. BMC Pregnancy Childbirth. 2019;19(1):323.

83. Maughan D, Molodynski A. An international perspective on the acceptability and sustainability of electroconvulsive therapy. BJPsych Int. 2016;13(1):10-2

84. Kim DR, Sockol L, Barber JP, Moseley M, Lamprou L, Rickels K, O'Reardon JP, Epperson CN. A survey of patient acceptability of repetitive transcranial magnetic stimulation (TMS) during pregnancy. J Affect Disord. 2011;129(13):385-90.

85. Simpson KN, Welch MJ, Kozel FA, Demitrack MA, Nahas Z. Cost-effectiveness of transcranial magnetic stimulation in the treatment of major depression: a health economics analysis. Adv Ther. 2009;26(3):346-68. 
86. Zhao YJ, Tor PC, Khoo AL, Teng M, Lim BP, Mok YM. Cost-effectiveness modeling of repetitive Transcranial magnetic stimulation compared to electroconvulsive therapy for treatment-resistant depression in Singapore. Neuromodulation. 2018;21(4):376-82.

87. Lancaster CA, Gold KJ, Flynn HA, Yoo H, Marcus SM, Davis MM. Risk factors for depressive symptoms during pregnancy: a systematic review. Am J Obstet Gynecol. 2010;202(1):5-14.

\section{Publisher's Note}

Springer Nature remains neutral with regard to jurisdictional claims in published maps and institutional affiliations.

Ready to submit your research? Choose BMC and benefit from:

- fast, convenient online submission

- thorough peer review by experienced researchers in your field

- rapid publication on acceptance

- support for research data, including large and complex data types

- gold Open Access which fosters wider collaboration and increased citations

- maximum visibility for your research: over $100 \mathrm{M}$ website views per year

At $\mathrm{BMC}$, research is always in progress.

Learn more biomedcentral.com/submissions 